\title{
Electrocatalytic hydrogen evolution with cobalt-poly(4-vinylpyridine) metallopolymers
}

\author{
Zeynep Kap ${ }^{1} \cdot$ Emine Ülker $^{1,2} \cdot$ Satya Vijaya Kumar Nune ${ }^{1} \cdot$ Ferdi Karadas $^{1,3}$ (D)
}

Received: 27 September 2017 / Accepted: 8 January 2018 / Published online: 13 January 2018

๑) Springer Science+Business Media B.V., part of Springer Nature 2018

\begin{abstract}
A facile synthetic pathway using poly(4-vinylpyridine) as a polypyridyl platform is reported for the formation of a metallopolymer. Electrochemical studies indicate that the metallopolymer acts as an efficient $\mathrm{H}_{2}$ evolution catalyst similar to cobalt polypyridyl complexes. It is also observed that the metallopolymer is transformed to cobalt particles when a cathodic potential is applied in the presence of an acid. Electrochemical measurements indicate that an FTO electrode coated with these cobalt particles also acts as an efficient hydrogen evolution catalyst. Approximately $80 \mu$ moles of $\mathrm{H}_{2}$ gas can be collected during $2 \mathrm{~h}$ of electrolysis at $-1.5 \mathrm{~V}\left(\mathrm{vs} . ~ \mathrm{Fc}^{+/ 0}\right)$ in the presence of $60 \mathrm{mM}$ of acetic acid. A comprehensive study of the electrochemical and electrocatalytic behavior of cobalt-poly(4-vinylpyridine) is discussed in detail.
\end{abstract}

\section{Graphical Abstract}

Poly(4-vinylpyridine) as a precursor for electrodeposited cobalt particles: a cobalt coat derived by a metallopolymer acts as an efficient $\mathrm{H}_{2}$ evolution catalyst. It can transform to a cobalt coat when a potential above $-1.1 \mathrm{~V}$ is applied in acid medium.

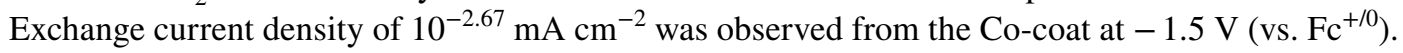
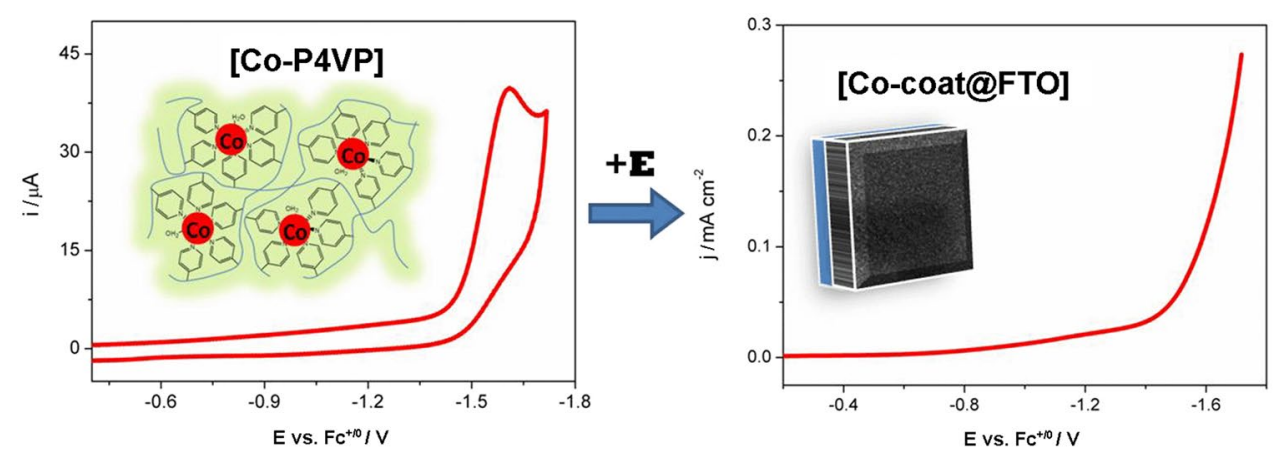

Keywords Cobalt $\cdot$ Electrodeposition $\cdot$ Hydrogen evolution $\cdot$ Poly(4-vinylpyridine) $\cdot$ Water reduction

Electronic supplementary material The online version of this article (https://doi.org/10.1007/s10800-018-1152-z) contains supplementary material, which is available to authorized users.

Emine Ülker

emine.kapancik@erdogan.edu.tr

$\triangle$ Ferdi Karadas

karadas@fen.bilkent.edu.tr

1 Department of Chemistry, Bilkent University, 06800 Ankara, Turkey
2 Department of Chemistry, Faculty of Arts \& Sciences, Recep Tayyip Erdogan University, 53100 Rize, Turkey

3 UNAM-Institute of Materials Science and Nanotechnology, Bilkent University, 06800 Ankara, Turkey 


\section{Introduction}

Much research has been devoted to the development of catalysts for hydrogen evolution, which is one of the most challenging steps in the development of the hydrogen economy [1-7]. Even though platinum is the best catalyst known to date, its high cost has encouraged researchers to find alternative highly efficient and abundant catalysts. Catalysts containing $\mathrm{Co}$ and $\mathrm{Ni}$ metal ions have been the pioneers in this field since several electrocatalysts such as cobalt diglyoxime complexes (also known as cobaloximes) [8-10], cobalt diamine-dioximes [11], cobalt polypyridyl complexes [2, 7, 12-14], nickel phosphines [1, 15-17], and cobalt sulfides [18] have been reported to evolve hydrogen from water efficiently.

Although molecular complexes are the central focus of current research, these complexes have a tendency to disintegrate under drastic electrocatalytic and photocatalytic conditions. For example, the debate on whether cobalt diamine-dioxime complexes degrade to form cobaltcontaining nanoparticles is still ongoing. Kaeffer et al. recently claimed that molecular complexes act as molecular catalysts in non-aqueous solutions, whereas they could transform to metal-based nanoparticles in acidic and/or aqueous solution and in the presence of an applied potential [19]. Recent studies focusing on such transformation processes indicate that the nanoparticles that are produced with this method could also act as efficient water reduction electrocatalysts. The synthetic strategy including the use of molecular systems as precursors for electroactive nanoparticles for water reduction was first reported by Anxolabéhère-Mallart et al. [20]. The origin of the catalytic activity of an intensely studied cobalt clathrochelate system, in which the cobalt site is buried inside a hexadentate ligand cavity, was one of the first controversies in the field of molecular hydrogen evolution catalysts because no catalytic activity was expected from such a sterically hindered cobalt site. It was later found that, in fact, the cobalt nanoparticles formed by the decomposition of the molecular cobalt complex were responsible for electrocatalytic water reduction. A follow-up study on a series of cobalt-trisglyoximato complexes with different ligand sets revealed that the potential for electrodeposition is highly dependent on the type of the ligand [21]. A recent study by Anxolabéhère-Mallart et al. led to the conclusion that the cobalt-bisglyoximato complex, which is not an active electrocatalyst for proton reduction can be altered in the presence of acid to cobalt-based nanoparticles, which are efficient electrocatalysts for proton reduction [22]. Such an electrodeposition process was observed not only for cobalt complexes with different ligands such as pyridine oxime [23] but also for metal complexes other than cobalt such as $\left[\mathrm{Ni}(\mathrm{N}-\mathrm{N}-\mathrm{SCH} 3)_{2}\right]\left(\mathrm{BF}_{4}\right)_{2}(\mathrm{~N}-\mathrm{N}-\mathrm{SCH} 3=2$-pyridyl- $N$ (2'-methylthiophenyl)methyleneimine) [24].

These deposited catalysts have the following key advantages over molecular systems: (i) an additional step for the deposition of the catalysts on the electrode is unnecessary due to their in situ synthesis on the electrode surface, and (ii) the deposited catalysts are much more stable compared to molecular systems under drastic electrocatalytic processes. Therefore, the aforementioned method involving the use of monometallic complexes as precursors to form water reduction catalysts should be investigated further.

In this study, a metallopolymer, cobalt poly(4-vinylpyridine) (P4VP), was used for the first time as a precursor for the preparation of cobalt-containing particles that can efficiently reduce protons to hydrogen. Polymers with pyridyl groups have been previously used to bind with transition metal ions such as ruthenium and copper to form metallopolymers. This study also outlines a detailed electrochemical investigation of cobalt-polymer systems as well as their transformation to cobalt-based particles, which are active electrocatalysts for $\mathrm{H}_{2}$ evolution.

\section{Experimental section}

\subsection{Starting materials}

Cobalt acetate, poly(4-vinylpyridine), acetic acid (99.8\%), and all solvents were of analytical grade and were obtained from Sigma-Aldrich and used without any further processing. The abbreviation, $\mathrm{CoAc}_{2}$ will be used for cobalt acetate and $\mathrm{AcOH}$ will be used for acetic acid throughout the article. Millipore deionized water (resistivity: $18 \mathrm{~m} \Omega \mathrm{cm}$ ) was used for all experiments.

\subsection{Synthesis of [Co-P4VP]}

$\mathrm{CoAc}_{2}$ and poly(4-vinylpyridine) (P4VP) (1:5) were mixed in a $1: 1 \mathrm{H}_{2} \mathrm{O} / \mathrm{MeCN}$ (\% volume per volume, v/v) mixture and used for electrochemical studies. Throughout the article, the abbreviation [Co-P4VP] will be used for the metallopolymer and $\mathrm{MeCN}$ will be used for acetonitrile.

\subsection{Electrochemistry}

Electrochemical experiments were performed at room temperature using a Gamry Instruments Interface 1000 Potentiostat/Galvanostat. A conventional three-electrode electrochemical cell was used with a glassy carbon disc electrode $(\mathrm{GCE})\left(\right.$ area $\left.=0.071 \mathrm{~cm}^{2}\right)$ as the working electrode and $\mathrm{at}$ wire as the counter electrode. The working electrode was cleaned after each measurement by polishing with an alumina $(0.05-\mu$ diameter) suspension followed by sonication 
with water. The pseudo-reference electrode was a silver wire immersed in $1: 1 \mathrm{H}_{2} \mathrm{O} / \mathrm{MeCN}(\mathrm{v} / \mathrm{v})$ mixture with $0.1 \mathrm{M}$ $\mathrm{KNO}_{3}$, which was separated from the solution by a glass frit. Ferrocene was used as an internal standard and all potentials were referenced versus the ferrocenium/ferrocene couple $\left(\mathrm{Fc}^{+/ 0}\right)(0.64 \mathrm{~V}$ vs. SHE). AcOH was used as the proton source in the hydrogen evolution experiments. All experiments were carried out under a nitrogen atmosphere.

\subsection{Formation of Co particles onto FTO}

A solution of [Co-P4VP] $(1 \mathrm{mM})$ in a $\mathrm{H}_{2} \mathrm{O} / \mathrm{MeCN}$ mixture $(1: 1 \mathrm{v} / \mathrm{v})$ containing $3 \mathrm{mM}$ of $\mathrm{AcOH}$ and $0.1 \mathrm{M}$ of $\mathrm{KNO}_{3}$ under nitrogen was electrolyzed at $-1.5 \mathrm{~V}\left(\mathrm{vs} . \mathrm{Fc}^{+/ 0}\right)$ for $2 \mathrm{~h}$ using fluorine-doped tin oxide (FTO) (area: $1 \mathrm{~cm}^{2}$ ) as the working electrode. The electrode was washed several times with an $\mathrm{H}_{2} \mathrm{O} / \mathrm{MeCN}$ mixture after coating. Cobalt particlecoated FTO is abbreviated as [Co-coat@FTO] throughout the article.

\subsection{Bulk water electrolysis}

The bulk electrolysis experiment was performed in a $\mathrm{H}_{2} \mathrm{O}$ / $\mathrm{MeCN}(1: 1 \mathrm{v} / \mathrm{v})$ mixture with $0.1 \mathrm{M}$ of $\mathrm{KNO}_{3}$ containing $60 \mathrm{mM}$ of $\mathrm{AcOH}$ at $-1.5 \mathrm{~V}\left(\mathrm{vs} . \mathrm{Fc}^{+/ 0}\right.$ ) for $2 \mathrm{~h}$. A Pt mesh counter electrode was separated from the rest of the solution by a glass frit. [Co-coat@FTO] was used as the working electrode.

\subsection{GC analysis}

The gas generated during the electrolysis was analyzed with an Agilent 7820A gas chromatograph equipped with a Molesieve GC column $(30 \mathrm{~m} \times 0.53 \mathrm{~mm} \times 25 \mu \mathrm{m})$ thermostatted at $40{ }^{\circ} \mathrm{C}$ and a TCD detector thermostatted at $100{ }^{\circ} \mathrm{C}$ for the detection of hydrogen $\left(\mathrm{H}_{2}\right)$. Argon was used as the carrier gas. To avoid cross-contamination, prior to each experiment, the electrochemical cell was purged with nitrogen for $20 \mathrm{~min}$. Then, $100 \mu \mathrm{L}$ aliquots of gas were collected from the headspace of the electrochemical cell over 10-min intervals with a gas-tight Hamilton syringe. The retention time of hydrogen was recorded as $0.77 \mathrm{~min}$.

\section{Results and discussion}

\subsection{Synthesis and characterization}

When $\mathrm{CoAc}_{2}$ was added to a suspension of P4VP in $\mathrm{H}_{2} \mathrm{O} / \mathrm{MeCN}$ mixture $(1: 1 \mathrm{v} / \mathrm{v})$, a clear pink solution was obtained, indicating the formation of a cationic metallopolymer. $\mathrm{CoAc}_{2}$ and P4VP were added in the stoichiometric ratio of 1:5 (Co:pyridine) to ensure that each cobalt ion is surrounded by an average of five pyridine groups and one solvent molecule. $\mathrm{N}$ 1s peak of XPS for P4VP positioned at $399 \mathrm{eV}$ showed a visible shift to a slightly higher binding energy in the resulting compound, indicating a variation in the charge due to the formation of $\mathrm{Co}-\mathrm{N}$ bonds (Fig. S1) [25]. Furthermore, the shoulder observed at $399 \mathrm{eV}$, can be attributed to the pyridyl groups of P4VP, which are not coordinated to cobalt ion.

\subsection{Electrocatalytic studies}

The cyclic voltammogram (CV) of [Co-P4VP] at a GCE in a $\mathrm{H}_{2} \mathrm{O} / \mathrm{MeCN}(1: 1 \mathrm{v} / \mathrm{v})$ mixture with $0.1 \mathrm{M}^{\circ} \mathrm{KNO}_{3}$ as a supporting electrolyte displays a redox potential at around

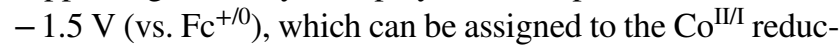
tion process (Fig. 1). The electrocatalytic proton reduction capacity of the [Co-P4VP] was studied in $\mathrm{H}_{2} \mathrm{O} / \mathrm{MeCN}$ mixture $(1: 1 \mathrm{v} / \mathrm{v})$ after addition of $\mathrm{AcOH}$ as the proton source. $\mathrm{CV}$ of [Co-P4VP] with $3 \mathrm{mM}$ of $\mathrm{AcOH}$ exhibits improved currents at more positive potentials closer to the $\mathrm{Co}^{\mathrm{II} / \mathrm{I}}$ wave. Furthermore, CV experiments performed with a GCE in the absence of catalyst and acid did not exhibit any catalytic current. A modest increase in the current is observed when acid is added to the solution in the absence of a catalyst. Then, a significant current is observed with the addition of the acid in a solution of [Co-P4VP] (1 mM). The comparison of the CVs mentioned above suggests that [Co-P4VP] is responsible for the electrocatalytic $\mathrm{H}_{2}$ evolution (Fig. 1). The $\mathrm{CVs}$ of the catalyst with and without acid are similar while a significantly higher current is obtained in the presence of [Co-P4VP]. CVs of $\mathrm{CoAc}_{2}$ in $\mathrm{H}_{2} \mathrm{O} / \mathrm{MeCN}$ in the absence and the presence of $3 \mathrm{mM}$ of $\mathrm{AcOH}$ were also obtained to compare the electrochemical behavior of the bare $\mathrm{Co}$ (II) precursor (Fig. S2) and [Co-P4VP]. No significant increase in the current of $\mathrm{CoAc}_{2}$ was observed compared to that of [Co-P4VP]. In addition, CV of a P4VP-coated GCE was measured since $\mathrm{P} 4 \mathrm{VP}$ is not soluble in $1: 1 \mathrm{H}_{2} \mathrm{O} / \mathrm{MeCN}(\mathrm{v} / \mathrm{v})$ mixture. $\mathrm{CV}$ s of $\mathrm{P} 4 \mathrm{VP}$-coated $\mathrm{GCE}$ in a $\mathrm{H}_{2} \mathrm{O} / \mathrm{MeCN}$ mixture (v/v 1:1) containing $0.1 \mathrm{M} \mathrm{KNO}_{3}$ supporting electrolyte with and without $3 \mathrm{mM}$ of $\mathrm{AcOH}$ reveal that P4VP itself did not contribute significantly to the electrocatalytic activity (Fig. S3a, b). Overall, a comparison of CVs obtained for bare $\mathrm{CoAc}_{2}$, bare $\mathrm{P} 4 \mathrm{VP}$, and [Co-P4VP] indicates that the target metallopolymer is the active catalyst in the presence of acid.

Electrochemical studies performed on [Co-P4VP] with different metal:ligand ratios of 1:5, 1:10, and 1:50 show similar electrochemical profiles (Fig. S4). Absorption spectra of these derivatives are similar as well (Fig. S5). A broad band at $506 \mathrm{~nm}\left(\varepsilon=12 \times 10^{3} \mathrm{M}^{-1} \mathrm{~cm}^{-1}\right.$ for Co-P4VP (1:5)) with a shoulder at $463 \mathrm{~nm}$ that could be attributed to a metal-toligand charge transfer (MLCT) transition was also observed; this band is similar to some of the previously reported $\mathrm{Co}$ (II) molecular systems [26]. The aforementioned similarities in 
Fig. 1 Comparison of cyclic voltammograms of blank GCE (dot), $3 \mathrm{mM}$ of AcOH blank (dash), $1 \mathrm{mM}$ of [Co-P4VP] (1:5) (dash dot), and $1 \mathrm{mM}$ of $[\mathrm{Co}-\mathrm{P} 4 \mathrm{VP}]$ in the presence of $3 \mathrm{mM}$ of AcOH (solid) in $1: 1 \mathrm{H}_{2} \mathrm{O} / \mathrm{MeCN}(\mathrm{v} / \mathrm{v})$ mixture with $0.1 \mathrm{M} \mathrm{KNO}_{3}$ at a $\operatorname{GCE}(\nu$ : $100 \mathrm{mV} \mathrm{s}^{-1}$ )

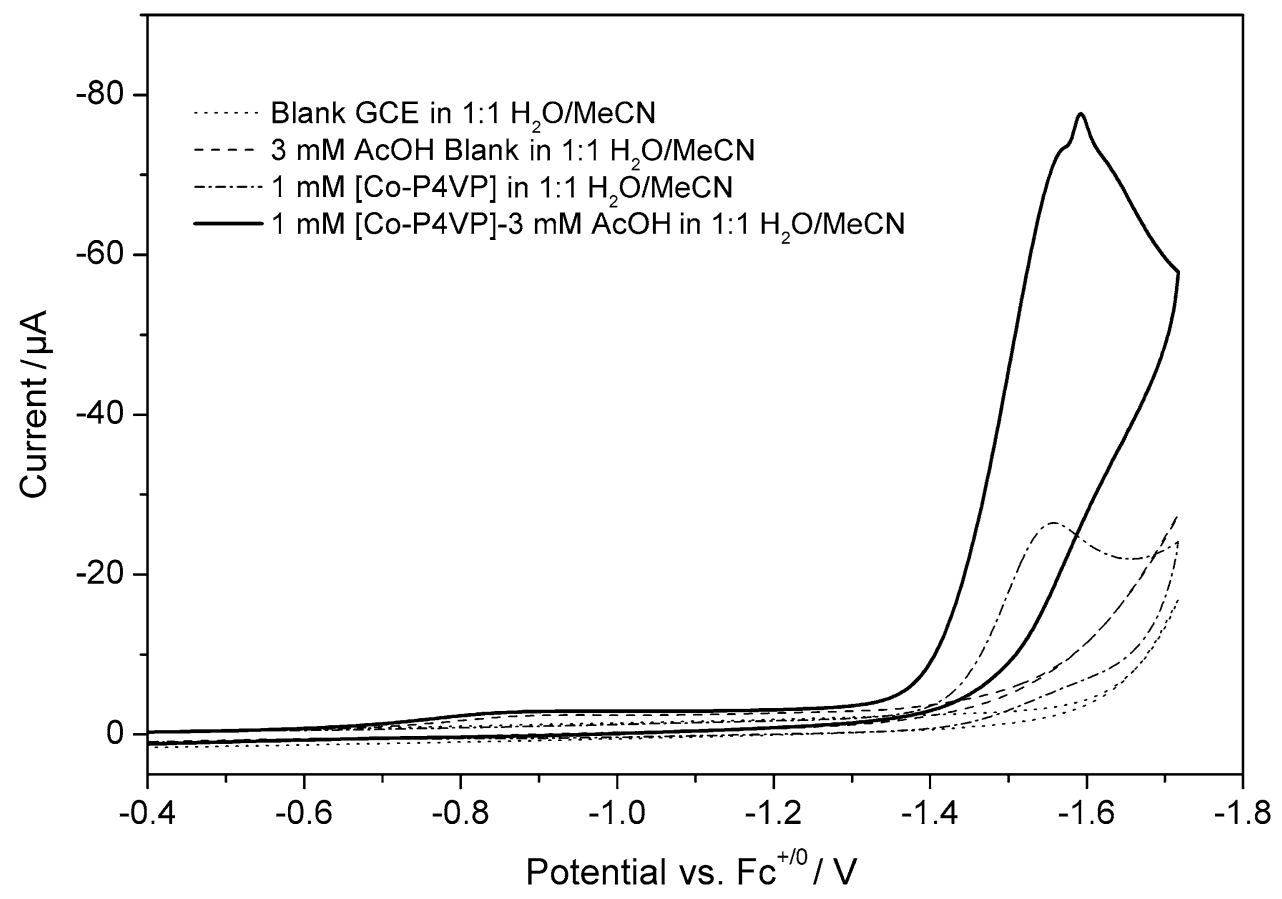

these derivatives suggest that cobalt ions in Co-P4VP systems have similar coordination environments irrespective of the metal:ligand ratio.

According to the literature, the overpotential for the catalytic water reduction process of the catalyst can be extracted from the lowest potential at which $\mathrm{AcOH}$ is reduced to dihydrogen [27]. The overpotential for [Co-P4VP] was derived as approximately $210 \mathrm{mV}$ when the half reaction potential for $\mathrm{AcOH}$ in $\mathrm{MeCN}$ is taken as $1.29 \mathrm{~V}$ versus $\mathrm{Fc}^{+/ 0}$ [28]. The obtained overpotential is similar to the value reported for $\left[\mathrm{Co}_{3}\left(\mathrm{C}_{6} \mathrm{H}_{11} \mathrm{O}_{2}\right)_{6}\right]\left[\mathrm{BF}_{4}\right]_{2}(175 \mathrm{mV})$ [29] and much lower than the reported overpotential for $\left[\mathrm{Co}\left(\mathrm{CF}_{3} \mathrm{SO}_{3}\right)(1,4\right.$-di(picolyl)7-(p-toluenesulfonyl)-1,4,7-triazacyclononane) $]\left[\mathrm{CF}_{3} \mathrm{SO}_{3}\right]$ $(590 \mathrm{mV})$ [27]. The comparison above is quite rough due to the assumption that $\mathrm{pKa}$ value of $\mathrm{AcOH}$ is identical in a $\mathrm{H}_{2} \mathrm{O} / \mathrm{MeCN}(1: 1 \mathrm{v} / \mathrm{v})$ mixture to that in $\mathrm{MeCN}$ since [Co-P4VP] is only partially soluble in pure $\mathrm{H}_{2} \mathrm{O}$ and $\mathrm{MeCN}$. The peak current of the wave $\left(I_{\mathrm{p}}\right)$ obtained in the presence of [Co-P4VP] increases linearly with the square root of the scan rate $\left(\nu^{1 / 2}\right)$, indicating a diffusion-controlled process (Fig. S6) [30]. A series of CV measurements were performed to determine the rate order of the electrocatalysis with respect to the concentration of [Co-P4VP] and AcOH (Fig. S7). The electrocatalytic $\mathrm{H}_{2}$ evolution capacity of [Co-P4VP] was investigated with increasing concentrations of $\mathrm{AcOH}$. The linear trend in the current with increasing acid concentration is a clear indication of the electrocatalytic $\mathrm{H}_{2}$ evolution (Fig. S8). The deviation from linearity at acid concentrations of above $5 \mathrm{mM}$ could be attributed to the deactivation of the complex. The electrode was polished before each CV scan to avoid the contribution from a possible adsorbed species. CVs have two characteristic features; a broad band due to the molecular cobalt ion and an irreversible spike that indicates the presence of an adsorbed species. The maximum point just before the spike (labeled as *) was, thus, used to investigate the electrocatalytic activity of [Co-P4VP]. The electrochemical behavior of [Co-P4VP] since a deactivation process, which was discussed below in detail, is observed above an acid concentration of $3 \mathrm{mM}$ and at relatively high negative overpotentials.

The plot of the catalytic current $\left(I_{\mathrm{c}}\right)$ versus concentration of [Co-P4VP] also exhibits linearity. The electrochemical studies systematically performed with increasing concentrations of [Co-P4VP] and AcOH indicate that catalytic hydrogen generation is first-order with respect to the concentration of [Co-P4VP] and is second-order with respect to $[\mathrm{AcOH}]$ at low concentrations as extracted using Eq. (1) [31].

$I_{\mathrm{c}}=\mathrm{nFA}[\mathrm{cat}] \sqrt{\mathrm{Dk}\left[\mathrm{H}^{+}\right]^{2}}$

A second-order reaction rate with respect to the concentration of the acid and a first-order rate with respect to the concentration of the catalyst indicates the presence of a water reduction process that involves $2 \mathrm{e}^{-}$and $2 \mathrm{H}^{+}$. The turnover frequency (TOF) of the catalyst could be extracted by plotting the slopes of these lines against $\nu^{-1 / 2}$ (Fig. 2) for a catalytic process that involves an electron transfer followed by a catalytic reaction $\left(E_{\mathrm{r}} C_{\mathrm{i}}{ }^{\prime}\right.$ scheme) [31]. A linear trend is obtained from the $I_{\mathrm{c}} / I_{\mathrm{p}}$ versus $[\mathrm{AcOH}]$ plots for different scan rates (where $I_{\mathrm{p}}$ is the peak current in the absence of acid) which is presented in Fig. S9 (Eq. 2). 
Fig. 2 Plot of the slopes versus $\nu^{-1 / 2}$. The linear fit is $1.2348 x+0.5843, R^{2}=0.983$. For $60 \mathrm{mM}[\mathrm{AcOH}]$, this corresponds to TOF of ca. $35 \mathrm{~mol}$ $\mathrm{H}_{2} /(\mathrm{mol}[\mathrm{Co}-\mathrm{P} 4 \mathrm{VP}] \times \mathrm{h})$

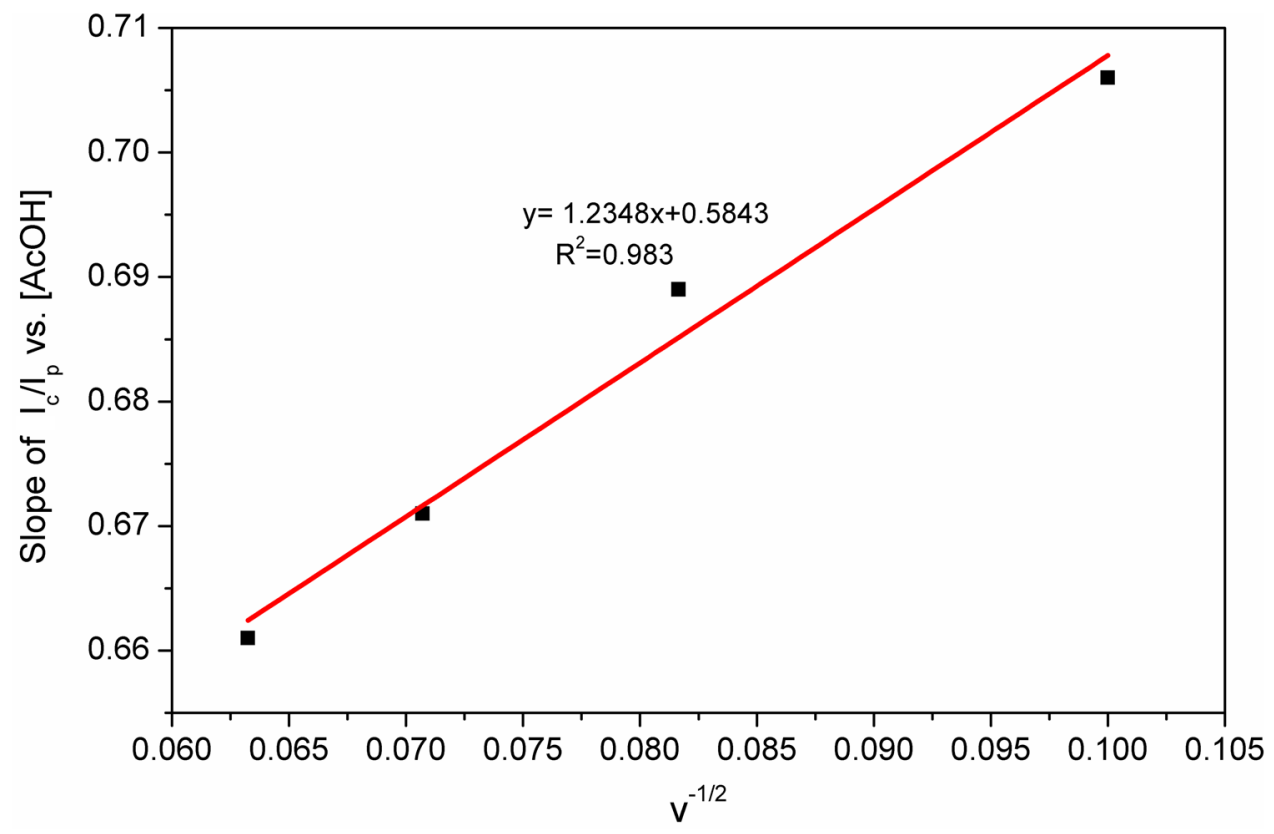

$$
\frac{I_{\mathrm{c}}}{I_{\mathrm{p}}}=\frac{n}{0.4463} \sqrt{\frac{\mathrm{RTk}\left[\mathrm{H}^{+}\right]^{2}}{\mathrm{Fv}}}
$$

TOF for the catalyst in the presence of $60 \mathrm{mM}$ of $\mathrm{AcOH}$ is calculated as $35 \mathrm{~h}^{-1}$, which is similar to the value reported for the CoPy4 system [31]. Here, it should be noted that [Co-P4VP] is completely deactivated at acid concentrations above $5 \mathrm{mM}$. Although the system cannot operate at an acid concentration of $60 \mathrm{mM}$, the similar electrochemical behavior and catalytic performances of a cobalt polypyridyl system and [Co-P4VP] suggest the formation of a metallopolymer in [Co-P4VP] that incorporates single cobalt site surrounded by pyridyl groups of P4VP. From the TOF value $\left(35 \mathrm{~mol} \mathrm{H}_{2} /(\mathrm{mol}[\mathrm{Co}-\mathrm{P} 4 \mathrm{VP}] \times \mathrm{h})\right), \mathrm{H}_{2}$ evolution was calculated as $0.058 \mathrm{mmol} \mathrm{mg}^{-1} \mathrm{~h}^{-1}$, which is higher than CoPy4 system $\left(0.047 \mathrm{mmol} \mathrm{mg}^{-1} \mathrm{~h}^{-1}\right)$ [31], cobalt(II) complex supported by 2-tetrahydrofurfurylamino- $N, N$-bis(2-methylene4-tert-butyl-6-methyl)phenol (0.029 mmol mg $\left.{ }^{-1} \mathrm{~h}^{-1}\right)$ [32], $\mathrm{MoS}_{2}$, and Ni2P (bulk) (0.038 and $0.039 \mathrm{mmol} \mathrm{mg}^{-1} \mathrm{~h}^{-1}$ ), respectively [33]. Furthermore, $\mathrm{H}_{2}$ production rate for various catalysts is listed in Table $\mathrm{S} 1$.

At low acid concentrations, the shape of the catalytic current wave is similar to the shape obtained in the absence of acid. However, $I_{\mathrm{c}}$ saturates at the concentrations above approximately $5 \mathrm{mM}$, and the rate of reaction becomes acid independent. Furthermore, an unusual irreversible spike labeled * was observed above acid concentrations of $3 \mathrm{mM}$ that increases with increasing concentration of the acid. Such irreversible sharp peaks which have not been observed in cobalt polypyridyl complexes previously reported in the literature are generally attributed to the adsorption of chemical species on the electrode surface (Fig. S8) [34]. Several studies have shown that cobalt complexes could act as precursors for the electrodeposition of nanoparticles to catalyze $\mathrm{H}_{2}$ evolution [20-22]. Rinse tests are usually used in electro-supported catalysis to investigate whether catalytically active, insoluble, and strongly attached species are deposited onto the electrode surface [35]. Therefore, a rinse test was performed to investigate the composition of the deposits on

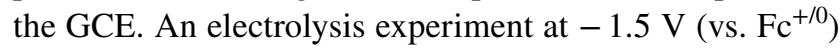
was performed with $1 \mathrm{mM}$ of [Co-P4VP] $\mathrm{H}_{2} \mathrm{O} / \mathrm{MeCN}(1: 1$ $\mathrm{v} / \mathrm{v}$ ) solution in the presence of $5 \mathrm{mM}$ of $\mathrm{AcOH}$ and $0.1 \mathrm{M}$ of $\mathrm{KNO}_{3}$ for $15 \mathrm{~min}$ using GCE (area: $0.071 \mathrm{~cm}^{2}$ ) as the working electrode. The electrode was then rinsed with an $\mathrm{H}_{2} \mathrm{O} / \mathrm{MeCN}$ mixture to eliminate weakly attached molecular species and was placed into a $5 \mathrm{mM} \mathrm{AcOH}$ solution in the absence of the catalyst. A comparison of $\mathrm{CV}$ profiles for the blank GCE and the GCE that was used for electrolysis indicates that the deposit also serves as a catalyst for water reduction because the $\mathrm{CV}$ of rinsed electrode exhibits a higher cathodic current compared to that of the blank electrode (Fig. S10). This result suggests that [Co-P4VP] transforms to cobalt-containing particles at more negative values than the potential of $-1.1 \mathrm{~V}$ in acidic media.

\subsection{Catalytic activity of [Co-coat@FTO]}

Co particles coated onto an FTO electrode, [Co-coat@ FTO] were formed by electrolysis of a $1 \mathrm{mM}$ of [Co-P4VP] in 1:1 $\mathrm{H}_{2} \mathrm{O} / \mathrm{MeCN}(\mathrm{v} / \mathrm{v})$ mixture containing $3 \mathrm{mM}$ of $\mathrm{AcOH}$ and $0.1 \mathrm{M}$ of $\mathrm{KNO}_{3}$ at $-1.5 \mathrm{~V}$ (vs. $\mathrm{Fc}^{+/ 0}$ ) for $2 \mathrm{~h}$. The modified FTO electrode was then rinsed and used as the working 
Fig. 3 LSV of blank FTO (black line) and [Co-coat@ FTO] obtained after electrolysis of $1 \mathrm{mM}$ [Co-P4VP] and $3 \mathrm{mM}$ AcOH $\mathrm{H}_{2} \mathrm{O} / \mathrm{MeCN}$ solution with $0.1 \mathrm{M} \mathrm{KNO}_{3}$ at an applied potential of $-1.5 \mathrm{~V}\left(\mathrm{vs} . \mathrm{Fc}^{+/ 0}\right)$ for $2 \mathrm{~h}\left(\nu: 100 \mathrm{mV} \mathrm{s}^{-1}\right)$. The inset shows the Tafel slope derived from LSV

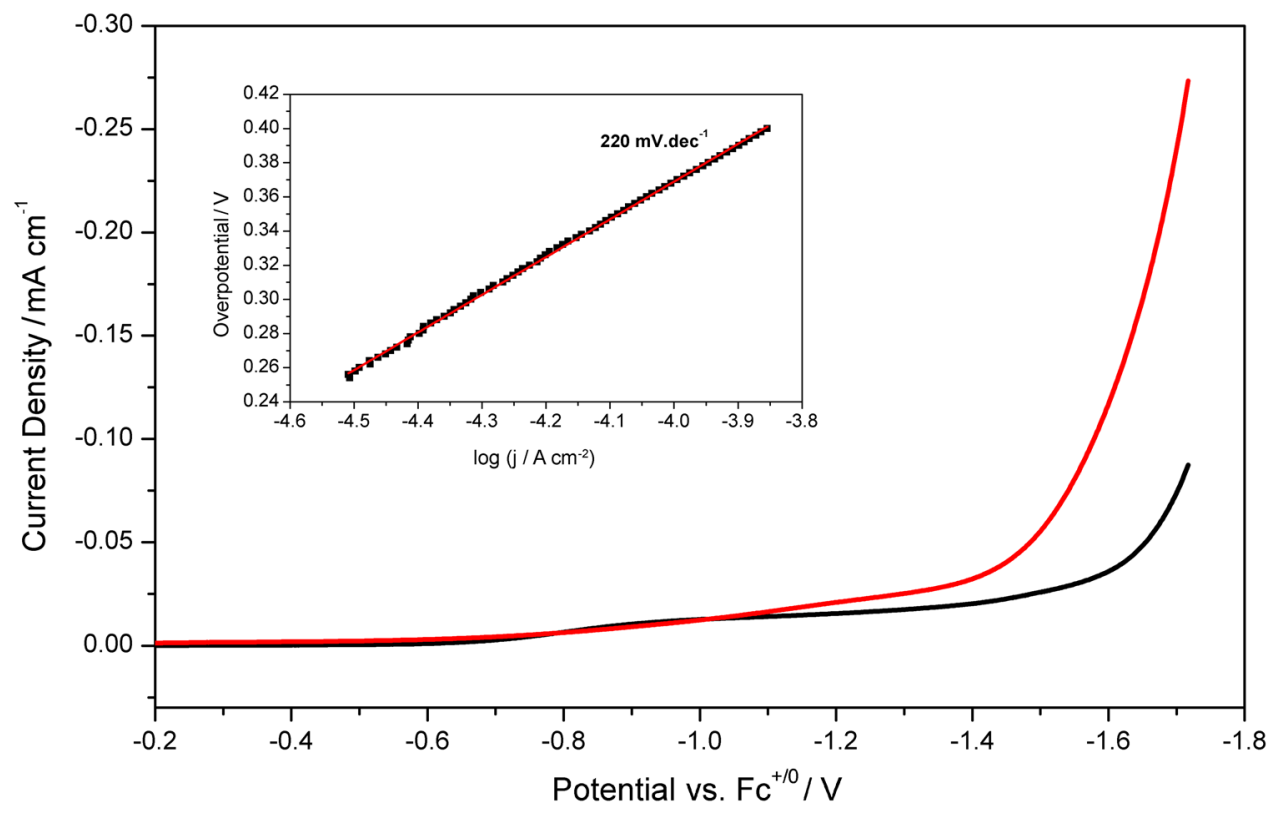

electrode for further electrochemical measurements. Figure 3 shows the linear sweep voltammogram (LSV) of [Co-coat@FTO]. A catalytic onset potential of $210 \mathrm{mV}$ is required to produce a current density of $55 \mu \mathrm{A} \mathrm{cm} \mathrm{cm}^{-2}$ and the Tafel slope of $220 \mathrm{mV} \mathrm{dec}^{-1}$ was derived from LSV analysis at a low scan rate. Although obtained at slightly different experimental conditions, the slope is similar to that of the Co nanoparticles electrodeposited from cobalt-bisglyoximato diphenyl complex solution $\left(200 \mathrm{mV} \mathrm{dec}^{-1}\right)$ [22], $\mathrm{Co}_{2} \mathrm{~B}-500$ (amorphous cobalt boride annealed at $500{ }^{\circ} \mathrm{C}$ ) (177 $\mathrm{mV} \mathrm{dec}^{-1}$ at higher current density) [36], and $\mathrm{Cu}-\mathrm{TPA}$ catalyst (copper(II) tris(2-pyridylmethyl)amine) (320 mV $\operatorname{dec}^{-1}$ ) [37], reported previously. A relatively high Tafel slope indicates that the mechanism of hydrogen evolution on [Co-coat@FTO] was similar to that of the Co nanoparticles and $\mathrm{Co}_{2} \mathrm{~B}-500$. Three classical theories are routinely used to explain the mechanisms underlying the evolution of hydrogen on metal surfaces. The first step of hydrogen evolution reaction (HER) is believed to be the proton discharge step (Volmer step, $120 \mathrm{mV} \mathrm{dec}^{-1}$ ) followed by electrochemi-

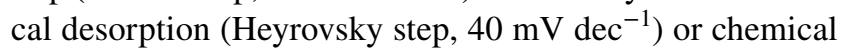
desorption (Tafel step, $30 \mathrm{mV} \mathrm{dec}^{-1}$ ) [38, 39]. The water discharge reaction (Volmer step) appears to be the dominant rate limiting step during the HER with Co particles [36]. The exchange current density $\left(j_{0}\right)$ of $10^{-2.67} \mathrm{~mA} \mathrm{~cm}^{-2}$ was determined from the Tafel plot and is similar to that obtained for Co nanoparticles electrodeposited from cobalt-bisglyoximato diphenyl complex, $10^{-2.7} \mathrm{~mA} \mathrm{~cm}^{-2}$ [22], electrodeposited Co-based film, $10^{-2.5} \mathrm{~mA} \mathrm{~cm}^{-2}$ geometric [40], and higher than that for electropolymerized $\mathrm{Co}$ (II) dibenzotetraaza(14) annulene system, $10^{-4.70} \mathrm{~mA} \mathrm{~cm}{ }^{-2}$ geometric [41].

A controlled potential electrolysis was also performed in a $1: 1 \mathrm{H}_{2} \mathrm{O} / \mathrm{MeCN}(\mathrm{v} / \mathrm{v})$ solution with $0.1 \mathrm{M}$ of $\mathrm{KNO}_{3}$ containing $60 \mathrm{mM}$ of $\mathrm{AcOH}$ at $-1.5 \mathrm{~V}$ for the quantitative measurement of the evolved $\mathrm{H}_{2}$. The results summarized in Fig. 4a indicate that a total of around $-17 \mathrm{C}$ of charge passed during the course of $2 \mathrm{~h}$ while $1 \mathrm{C}$ was collected during a $5 \mathrm{~h}$ experiment at $-0.75 \mathrm{~V}$ versus NHE using Co nanoparticles prepared from boron-capped tris(glyoximato) cobalt clathrochelate [20] and $3 \mathrm{C}$ of charge was obtained at $-1 \mathrm{~V}$ versus SCE using a cobalt-bisglyoximato diphenyl complex [22]. It should be noted that the aforementioned studies were performed at different experimental conditions, making it difficult to make any comparisons. A $100 \mu \mathrm{L}$ aliquot of gas collected from the headspace of the electrolysis cell was transferred with a gas-tight syringe to obtain a gas chromatogram (Fig. S11). Current efficiency of $91 \%$ for $\mathrm{H}_{2}$ production catalyzed by [Co-coat@FTO] was calculated using the moles of $\mathrm{H}_{2}$ produced $(0.081 \mathrm{mmol})$ and the charge passed (-17C) during the electrolysis (Fig. 4b). This clearly indicates that the Co-based particles formed during the electrolysis serve as the active species for $\mathrm{H}_{2}$ evolution.

\subsection{Characterization of electrodes}

Figure 5 depicts the XPS spectra of Co $2 p$ signals of the Co particles coated onto the FTO compared to the Co $2 p$ signals of the $\mathrm{Co}$ (II) precursor and [Co-P4VP]. Co $2 p_{3 / 2}$ and $2 p_{1 / 2}$ signals of [Co-P4VP] were observed as broad peaks at 782.38 and $798.08 \mathrm{eV}$, respectively, with FWHM of approximately 2-2.5 eV in [Co-P4VP], which corresponds well with the Co(II) precursor data (782.28 and $798.38 \mathrm{eV}$, respectively), indicating the absence of a significant change in the oxidation state [42]. Moreover, distinctive and scalable satellite signals were also observed at binding energies $4-5 \mathrm{eV}$ higher than the principal signals. 


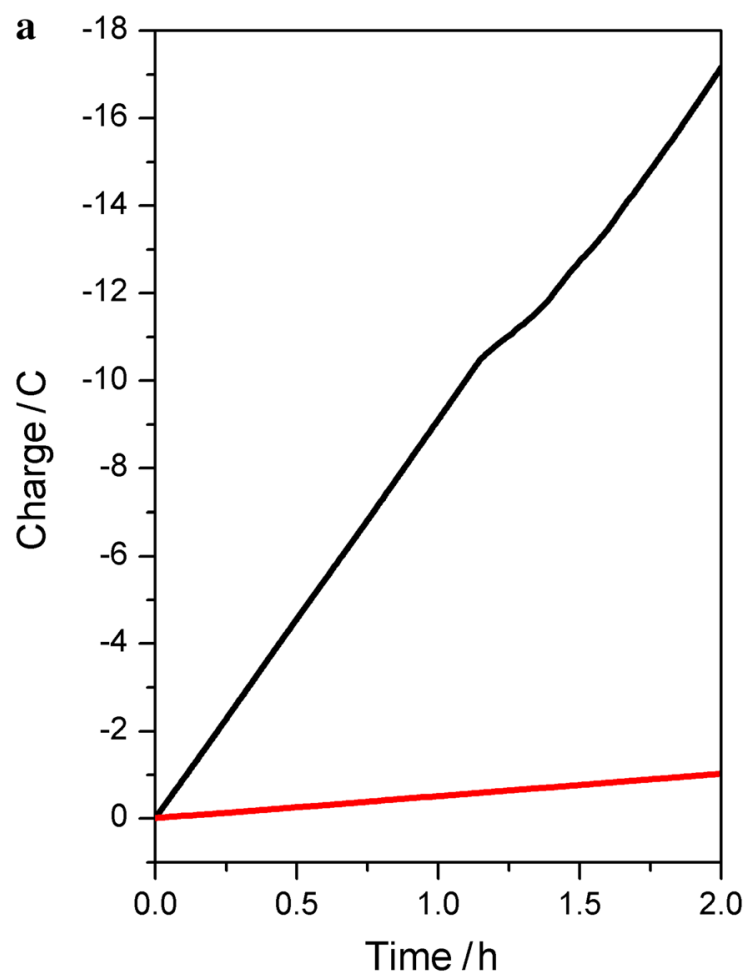

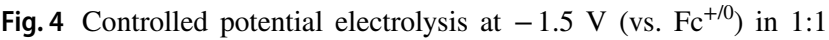
$\mathrm{H}_{2} \mathrm{O} / \mathrm{MeCN}$ with $0.1 \mathrm{M} \mathrm{KNO}_{3}$ and $60 \mathrm{mM} \mathrm{AcOH}$. a Charge versus time blank FTO (red line) and [Co-coat@FTO] (black line). b $\mathrm{H}_{2}$ pro-

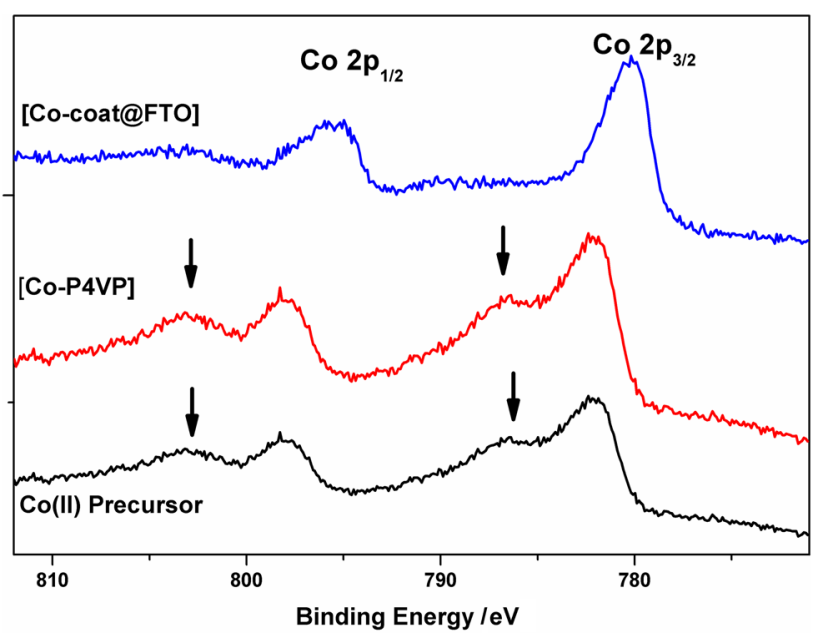

Fig. 5 XPS spectra of Co $2 p$ signals of Co(II) precursor, [Co-P4VP] and [Co-coat@FTO]

However, Co $2 p$ signals of the [Co-coat@FTO] show only a mild shift. Co $2 p_{3 / 2}$ and Co $2 p_{1 / 2}$ signals were observed as strong intense peaks at 780 and $795 \mathrm{eV}$, respectively, with FWHM of approximately $2.5-3 \mathrm{eV}$ with insignificant or negligible satellite signals. The mild shift in the position of the principle signals and insignificant satellite signals infers the

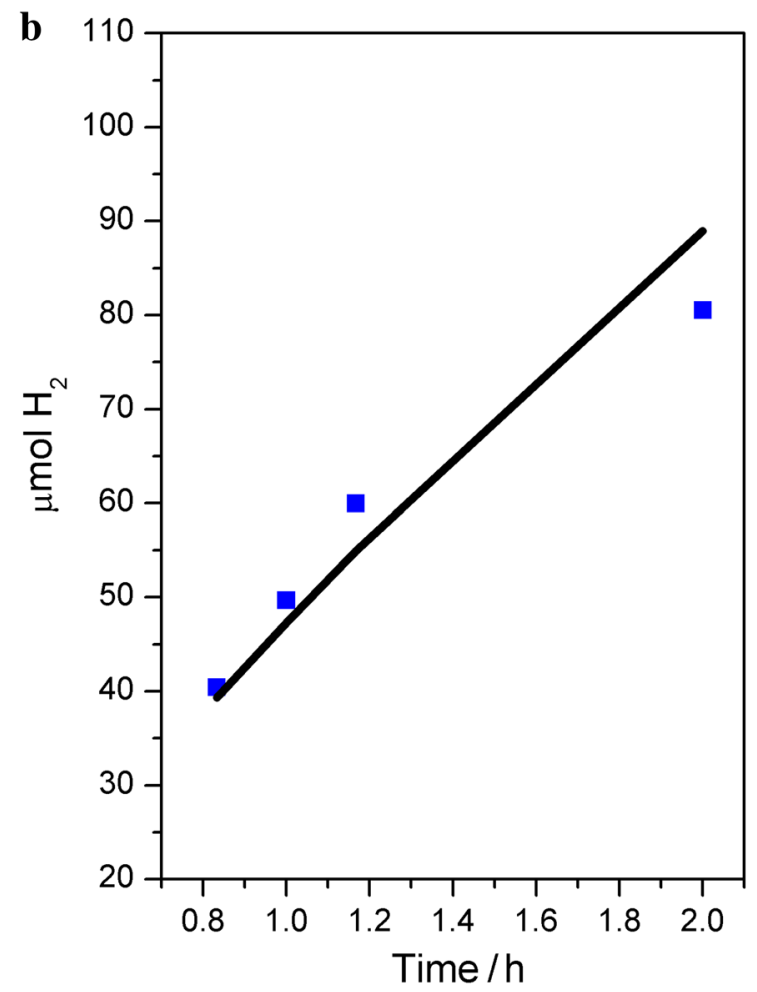

duced with [Co-coat@FTO] versus time confirmed by GC. The quantity of $\mathrm{H}_{2}$ ( $\left.\mu \mathrm{mol}\right)$ is integrated from GC (blue squares) and Faraday's Law assuming 91\% Faraday's yield (black line). (Color figure online)

presence of a mixture of oxidation states. Similar studies of $\mathrm{N}$ 1s and $\mathrm{C}$ 1s signals (Fig. S12a, b) reveal that the Co particles coated onto the FTO electrode exhibit a different chemical nature from [Co-P4VP]. $\mathrm{N}$ 1s and $\mathrm{C} 1 \mathrm{~s}$ signals of the coating deposited on the FTO correspond well with the P4VP precursor, indicating no evident decomposition in the pyridine ring or the P4VP chains. Furthermore, SEM images of the [Co-coat@FTO] (Fig. S13) exhibit a continuous film of particles, which is in good agreement with the XPS analysis findings.

\section{Conclusion}

While cobalt polypyridyl complexes have received much attention as electrocatalysts for $\mathrm{H}_{2}$ evolution, to date, no studies focusing on the electrocatalytic behavior of cobalt systems with pyridyl containing polymers have been reported. Although the exact coordination environment of cobalt ions in [Co-P4VP] cannot be made, the electrochemical profile and electrocatalytic activity of [Co-P4VP] suggest that the molecular cobalt systems surrounded with pyridyl groups are active sites in [Co-P4VP]. Furthermore, detailed electrochemical studies followed by XPS studies clearly show that molecular systems with single-metal sites 
can be obtained when the cobalt ion reacted with poly(4vinylpyridine). At low acid concentrations, electrocatalytic activity for $\mathrm{H}_{2}$ evolution process, which is similar to cobalt polypyridyl complexes, was observed. A cobalt polypyridyl system, Co ${ }^{\text {II }}$-PY4 (2-bis(2-pyridyl)(methoxy)methyl6-pyridylpyridine) in MeCN, exhibits the TOF of $40 \mathrm{~h}^{-1}$ in the presence of $60 \mathrm{mM}$ trifluoroacetic acid while a similar performance $\left(\mathrm{TOF}=35 \mathrm{~h}^{-1}\right.$ ) is observed for [Co-P4VP] in more demanding conditions $\left(1: 1 \mathrm{H}_{2} \mathrm{O} / \mathrm{MeCN}(\mathrm{v} / \mathrm{v})\right.$ mixture and $60 \mathrm{mM} \mathrm{AcOH}$ ). Such cobalt-polymer systems have the following advantages over cobalt polypyridyl complexes: (1) synthesis of pyridyl containing polymers is rather straightforward compared to those of the polypyridyl complexes and (2) the diverse chemistry of polymers can be used further to tune the electrochemical stability of the cobalt-polymer systems. The work focusing on the use of polymers with chelating bipyridine and terpyridine units and copolymers with a combination of these repeating units to enhance the stability of molecular cobalt-polymer systems at high cathodic potentials is in progress. Such a methodology will also help us to investigate the effect of second coordination sphere in molecular catalysts.

When a cathodic potential of $-1.1 \mathrm{~V}$ is applied in the presence of acid, [Co-P4VP] transforms to cobalt-based particles. Approximately $80 \mu$ moles of $\mathrm{H}_{2}$ gas was collected

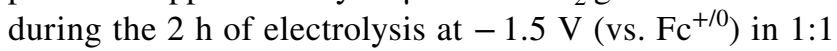
$\mathrm{H}_{2} \mathrm{O} / \mathrm{MeCN}$ mixture in the presence of $60 \mathrm{mM} \mathrm{AcOH}$, which was confirmed by both the amount of coulombs passed and gas chromatography. The exchange current density of $10^{-2.67}$ $\mathrm{mA} \mathrm{cm}{ }^{-2}$ was obtained from the Tafel slope, which is comparable with that of the electrodeposited cobalt-based catalyst, $\mathrm{H} 2-\mathrm{CoCat}\left(10^{-2.5} \mathrm{~mA} \mathrm{~cm}^{-2}\right)$, and cobalt foil $\left(10^{-3} \mathrm{~mA}\right.$ $\mathrm{cm}^{-2}$ ). XPS studies indicate that [Co-coat@FTO] is composed of cobalt sites with multiple oxidation states that are surrounded by poly(4-vinylpyridine).

The promising catalytic activity of the nanoparticles clearly shows that the use of metallopolymers is a viable and facile approach to prepare active electrocatalysts for $\mathrm{H}_{2}$ evolution and can be a new direction for the development of efficient and robust catalysts for hydrogen evolution from water.

Acknowledgements The authors thank the Science and Technology Council of Turkey, TUBITAK (Project No: 215Z249) for financial support. Emine Ülker thanks TUBITAK for support (Project No: 1929B011500059).

\section{References}

1. Helm ML, Stewart MP, Bullock RM et al (2011) A synthetic nickel electrocatalyst with a turnover frequency above 100,000 s-1 for $\mathrm{H} 2$ production. Science 333:863-866
2. Zee DZ, Chantarojsiri T, Long JR, Chang CJ (2015) Metalpolypyridyl catalysts for electro- and photochemical reduction of water to hydrogen. Acc Chem Res 48:2027-2036. https://doi. org/10.1021/acs.accounts.5b00082

3. Eckenhoff WT, McNamara WR, Du P, Eisenberg R (2013) Cobalt complexes as artificial hydrogenases for the reductive side of water splitting. Biochim Biophys Acta 1827:958-973. https:// doi.org/10.1016/j.bbabio.2013.05.003

4. McKone JR, Marinescu SC, Brunschwig BS et al (2014) Earthabundant hydrogen evolution electrocatalysts. Chem Sci 5:865878. https://doi.org/10.1039/C3SC51711J

5. Losse S, Vos JG, Rau S (2010) Catalytic hydrogen production at cobalt centres. Coord Chem Rev 254:2492-2504. https://doi. org/10.1016/j.ccr.2010.06.004

6. Du P, Eisenberg R (2012) Catalysts made of earth-abundant elements $(\mathrm{Co}, \mathrm{Ni}, \mathrm{Fe})$ for water splitting: recent progress and future challenges. Energy Environ Sci 5:6012. https://doi.org/10.1039/ c2ee03250c

7. Queyriaux N, Jane RT, Massin J et al (2015) Recent developments in hydrogen evolving molecular cobalt(II)-polypyridyl catalysts. Coord Chem Rev 304-305:3-19. https://doi.org/10.1016/j. ccr.2015.03.014

8. Dempsey JL, Brunschwig BS, Winkler JR, Gray HB (2009) Hydrogen evolution catalyzed by cobaloximes. Acc Chem Res 42:1995-2004. https://doi.org/10.1021/ar900253e

9. Razavet M, Artero V, Fontecave M (2005) Proton electroreduction catalyzed by cobaloximes: functional models for hydrogenases. Inorg Chem 44:4786-4795. https://doi.org/10.1021/ic050167z

10. Reuillard B, Warnan J, Leung JJ et al (2016) A poly(cobaloxime)/ carbon nanotube electrode: freestanding buckypaper with polymer-enhanced H2-evolution performance. Angew Chem Int Ed 55:3952-3957. https://doi.org/10.1002/anie.201511378

11. Kaeffer N, Chavarot-Kerlidou M, Artero V (2015) Hydrogen evolution catalyzed by cobalt diimine-dioxime complexes. Acc Chem Res 48:1286-1295. https://doi.org/10.1021/acs.accounts.5b00058

12. Khnayzer RS, Thoi VS, Nippe M et al (2014) Towards a comprehensive understanding of visible-light photogeneration of hydrogen from water using cobalt(ii) polypyridyl catalysts. Energy Environ Sci 7:1477. https://doi.org/10.1039/c3ee43982h

13. Rodenberg A, Orazietti M, Probst B et al (2015) Mechanism of photocatalytic hydrogen generation by a polypyridyl-based cobalt catalyst in aqueous solution. Inorg Chem 54:646-657. https://doi. org/10.1021/ic502591a

14. Vennampalli M, Liang G, Katta L et al (2014) Electronic effects on a mononuclear Co complex with a pentadentate ligand for catalytic $\mathrm{H}_{2}$ evolution. Inorg Chem 53:10094-10100. https://doi. org/10.1021/ic500840e

15. Yang JY, Bullock RM, DuBois MR, DuBois DL (2011) Fast and efficient molecular electrocatalysts for $\mathrm{H}_{2}$ production: using hydrogenase enzymes as guides. MRS Bull 36:39-47. https://doi. org $/ 10.1557 / \mathrm{mrs} .2010 .8$

16. Pool DH, DuBois DL (2009) [Ni(PPh2NAr2)2(NCMe)][BF4]2 as an electrocatalyst for $\mathrm{H}_{2}$ production: $\mathrm{PPh} 2 \mathrm{NAr} 2=1,5-(\mathrm{di}(4-$ (thiophene-3-yl)phenyl)-3,7-diphenyl-1,5-diaza-3,7-diphosphacyclooctane). J Organomet Chem 694:2858-2865. https://doi. org/10.1016/j.jorganchem.2009.04.010

17. Seo J, Pekarek RT, Rose MJ (2015) Photoelectrochemical operation of a surface-bound, nickel-phosphine $\mathrm{H}_{2}$ evolution catalyst on $\mathrm{p}-\mathrm{Si}(111)$ : a molecular semiconductor catalyst construct. Chem Commun 51:4-7. https://doi.org/10.1039/C5CC02802G

18. Sun Y, Liu C, Grauer DC et al (2013) Electrodeposited cobaltsulfide catalyst for electrochemical and photoelectrochemical hydrogen generation from water. J Am Chem Soc 135:1769917702. https://doi.org/10.1021/ja4094764

19. Kaeffer N, Morozan A, Fize J et al (2016) The dark side of molecular catalysis: diimine-dioxime cobalt complexes are not 
the actual hydrogen evolution electrocatalyst in acidic aqueous solutions. ACS Catal 6:3727-3737. https://doi.org/10.1021/ acscatal.6b00378

20. Anxolabéhère-Mallart E, Costentin C, Fournier M et al (2012) Boron-capped tris(glyoximato) cobalt clathrochelate as a precursor for the electrodeposition of nanoparticles catalyzing $\mathrm{H}_{2}$ evolution in water. J Am Chem Soc 134:6104-6107. https://doi. org/10.1021/ja301134e

21. El Ghachtouli S, Fournier M, Cherdo S et al (2013) Monometallic cobalt-trisglyoximato complexes as precatalysts for catalytic $\mathrm{H}_{2}$ evolution in water. J Phys Chem C 117:17073-17077. https://doi. org/10.1021/jp405134a

22. Anxolabéhère-Mallart E, Costentin $\mathrm{C}$, Fournier M, Robert M (2014) Cobalt-bisglyoximato diphenyl complex as a precatalyst for electrocatalytic $\mathrm{H}_{2}$ evolution. J Phys Chem C 118:1337713381. https://doi.org/10.1021/jp500813r

23. El Ghachtouli S, Guillot R, Brisset F, Aukauloo A (2013) Cobaltbased particles formed upon electrocatalytic hydrogen production by a cobalt pyridine oxime complex. ChemSusChem 6:22262230. https://doi.org/10.1002/cssc.201300564

24. Martin DJ, McCarthy BD, Donley CL, Dempsey JL (2014) Electrochemical hydrogenation of a homogeneous nickel complex to form a surface adsorbed hydrogen-evolving species. Chem Commun 51:2-5. https://doi.org/10.1039/c4cc08662g

25. Katoh T, Imamura G, Obata S, Saiki K (2016) Growth of N-doped graphene from nitrogen containing aromatic compounds: the effect of precursors on the doped site. RSC Adv 6:13392-13398. https://doi.org/10.1039/C5RA22664C

26. Mulyana Y, Alley KG, Davies KM et al (2014) Dinuclear cobalt(II) and cobalt(III) complexes of bis-bidentate napthoquinone ligands. Dalton Trans 43:2499-2511. https://doi. org/10.1039/C3DT52811A

27. Call A, Codolà Z, Acuña-Parés F, Lloret-Fillol J (2014) Photo- and electrocatalytic $\mathrm{H}_{2}$ production by new first-row transition-metal complexes based on an aminopyridine pentadentate ligand. Chem A Eur J 20:6171-6183. https://doi.org/10.1002/chem.201303317

28. Fourmond V, Jacques P-A, Fontecave M, Artero V (2010) $\mathrm{H}_{2}$ evolution and molecular electrocatalysts: determination of overpotentials and effect of homoconjugation. Inorg Chem 49:1033810347. https://doi.org/10.1021/ic101187v

29. Ahn HS, Davenport TC, Tilley TD (2014) Molecular cobalt electrocatalyst for proton reduction at low overpotential. Chem Commun 50:3834-3837. https://doi.org/10.1039/c3cc49682a

30. Wilson AD, Newell RH, McNevin MJ et al (2006) Hydrogen oxidation and production using nickel-based molecular catalysts with positioned proton relays. J Am Chem Soc 128:358-366. https:// doi.org/10.1021/ja056442y
31. Bigi JP, Hanna TE, Harman WH et al (2010) Electrocatalytic reduction of protons to hydrogen by a water-compatible cobalt polypyridyl platform. Chem Commun 46:958-960. https://doi. org/10.1039/B915846D

32. Lin C-N, Zhou L-L, Fu L-Z et al (2015) Synthesis, structure and electrochemical properties of a cobalt(II) complex supported by 2-tetrahydrofurfurylamino-N,N-bis(2-methylene-4-tert-butyl6-methyl)phenol. INOCHE 61:97-99. https://doi.org/10.1016/j. inoche.2015.08.017

33. MacDonald L, McGlynn JC, Irvine N et al (2017) Using earth abundant materials for the catalytic evolution of hydrogen from electron-coupled proton buffers. Sustain Energy Fuels 1:17821787. https://doi.org/10.1039/C7SE00334J

34. Jurss JW, Concepcion JC, Norris MR et al (2010) Surface catalysis of water oxidation by the blue ruthenium dimer. Inorg Chem 49:3980-3982. https://doi.org/10.1021/ic100469x

35. McCrory CCL, Uyeda C, Peters JC (2012) Electrocatalytic hydrogen evolution in acidic water with molecular cobalt tetraazamacrocycles. J Am Chem Soc 134:3164-3170. https://doi.org/10.1021/ ja210661k

36. Masa J, Weide P, Peeters D et al (2016) Amorphous cobalt boride $\left(\mathrm{Co}_{2} \mathrm{~B}\right)$ as a highly efficient nonprecious catalyst for electrochemical water splitting: oxygen and hydrogen evolution. Adv Energy Mater 6:1502313. https://doi.org/10.1002/aenm.201502313

37. Liu X, Zheng H, Sun Z et al (2015) Earth-abundant copper-based bifunctional electrocatalyst for both catalytic hydrogen production and water oxidation. ACS Catal 5:1530-1538. https://doi. org/10.1021/cs501480s

38. Zeng K, Zhang D (2010) Recent progress in alkaline water electrolysis for hydrogen production and applications. Prog Energy Combust Sci 36:307-326. https://doi.org/10.1016/j. pecs.2009.11.002

39. Faber MS, Jin S (2014) Earth-abundant inorganic electrocatalysts and their nanostructures for energy conversion applications. Energy Environ Sci 7:3519-3542. https://doi.org/10.1039/ C4EE01760A

40. Cobo S, Heidkamp J, Jacques P-A et al (2012) A Janus cobaltbased catalytic material for electro-splitting of water. Nat Mater 11:802-807. https://doi.org/10.1038/nmat3385

41. Rioual S, Lescop B, Quentel F, Gloaguen F (2015) A molecular material based on electropolymerized cobalt macrocycles for electrocatalytic hydrogen evolution. Phys Chem Chem Phys 17:13374-13379. https://doi.org/10.1039/C5CP01210D

42. Mclntyre NS, Cook MG (1975) X-ray photoelectron studies on some oxides and hydroxides of cobalt, nickel, and copper. Anal Chem 47:2208-2213. https://doi.org/10.1021/ac60363a034 